Analyses of topical policy issues

\title{
The iceberg decomposition: A parsimonious way to map the health of labour markets
}

\author{
Stijn Baert ${ }^{1}$ \\ Ghent University, Sint-Pietersplein 6, B-9000 Ghent, Belgium
}

\section{A R T I C L E I N F O}

\section{Article history:}

Received 18 July 2020

Received in revised form 9 December 2020

Accepted 10 December 2020

Available online 16 December 2020

JEL classification:
J64
J08
J23
J24
J68

Keywords:

Employment

Unemployment

Inactivity

Labour market policy

Labour market indicators

\begin{abstract}
A B S T R A C T
This article introduces the metaphor of the iceberg in the labour market. While policy in most OECD countries has historically focussed on reducing unemployment (the tip of the iceberg), the group of inactive people (below the waterline) is much larger. Therefore, we point to the clear limitations of the unemployment rate as the (single) key macro-economic indicator of the health of the labour market. A parsimonious dashboard approach utilising the unemployment-to-population ratio and the inactivityto-population ratio as two highly appropriate and complementary measures is defended. We show that the ratio of these two indices varies greatly between countries, which calls for different policies for different countries.

(c) 2020 Economic Society of Australia, Queensland. Published by Elsevier B.V. This is an open access article under the CC BY-NC-ND license (http://creativecommons.org/licenses/by-nc-nd/4.0/).
\end{abstract}

Adequate labour market policy is based on clear indicators. These indicators allow countries and regions to be compared with each other and over time, thus revealing the pain points on which that policy should focus. Despite the emergence of other indicators such as the participation rate and the proportion of discouraged and involuntary part-time workers (see, e.g., Brandolini and Viviano, 2018; European Commission, 2018; ILO, 2016), the unemployment rate and the employment rate are still by far the most frequently reported indicators in this respect (Borjas, 2015; Diamond, 2013; ECB, 2017; Elsby et al., 2015; Hornstein et al., 2014a,b; ILO, 2008, 2016; Sylla, 2013).

The employment rate of a particular age group (often the 20- to 64-year-old or 25- to 64-year-old group) is the percentage of employed persons in relation to the full population in this age group. It is often referred to as the employment-to-population ratio. The unemployment rate of a particular age group is the percentage of unemployed persons in relation to the active population (i.e., those who are employed or unemployed) in this age group. According to the widely used International Labour Organization (ILO) definition, a person is employed when (s)he is engaged in any activity used to produce goods or provide services for pay or profit (during at least one hour during the reference period), and a person is unemployed when (s)he is: (i) without work during the reference period, (ii) currently available for work and (iii) seeking work. Persons who are neither employed nor unemployed are labelled as inactive. In addition to older students, important subgroups in the inactive group are the discouraged unemployed, househusbands and housewives, the long-term sick and early retirees (ILO, 2008, 2016).

E-mail address: Stijn.Baert@UGent.be.

URL: http://www.stijnbaert.be.

1 The author is grateful to his top colleague Luc Van Ootegem and two anonymous reviewers for their constructive comments that helped to improve this study substantially. 
Both the unemployment rate and the employment rate have advantages and disadvantages. The main criticism of the unemployment rate is that it does not fully reflect the actual labour underutilisation present in the labour market, although it is often interpreted as doing so by policy makers (Borjas, 2015; Diamond, 2013; ECB, 2017; Elsby et al., 2015; Hornstein et al., 2014a,b; ILO, 2008, 2016; Sylla, 2013). This criticism is based on the fact that, as mentioned previously, the unemployment rate is calculated in relation to the active population and not in relation to the entire population within a given age group. Hence, the inactive group is excluded completely from this calculation. Given that the inactive group includes individuals who, under certain conditions, would be willing to work, the unemployment rate only shows 'the most visible part of labour underutilisation', while 'hidden unemployment' is not visible (Borjas, 2015; Sengenberger, 2011). Therefore, a comparison of the unemployment rate between countries makes little sense if the size of the inactive subpopulation is not considered. In view of the financing of social security, an unemployment rate of $7 \%$ is a much greater problem when $30 \%$ of people between 25 and 64 years of age are inactive, as opposed to only $15 \%$ of this group being inactive. Therefore, when used separately from other indicators, the unemployment rate is not necessarily a good guide for economic policy.

The employment rate offers a better insight into the underutilisation of resources in the labour market and, from a policy perspective, into how many workers are able to support the group of non-working people. A disadvantage of the employment rate, however, is that it does not allow a distinction to be made between the unemployed and the inactive. This lack of distinction is problematic because the distances to the labour market for these two groups differ substantially (Brandolini and Viviano, 2016, 2018; Hornstein et al., 2014a), indicating that the activation of these two groups requires different policies. A relatively high level of inactivity suggests a supply-oriented policy may be more appropriate, with, potentially, a focus on limiting the inactivity trap (i.e., the net income when employed is not substantially higher than the net income in inactivity). In the case of relatively high unemployment, more focus should be put on stimulating the demand for labour and matching supply and demand. High unemployment requires that activation policies focus strongly on guiding, monitoring and sanctioning the unemployed, while high inactivity requires additional attention be paid to the reintegration of welfare recipients and long-term sick. As a result, the same employment rate in two different countries may require completely different policies. Hence, a one-sided focus on the employment rate is not appropriate as well.

Moreover, a one-sided focus on either of these two commonly used indicators implies a normative choice. After all, a policy that focuses exclusively on reducing the unemployment rate qualifies inactivity as the free choice of an individual, equivalent to employment. At the same time, focusing on a global increase in the employment rate requires the activation of inactive workers in order to show significant improvement (and qualifies employment as being superior to inactivity). Either approach underlines once again that the one-sided use of the unemployment rate or the employment rate, which regularly occurs today in academic research and policy studies, is unsatisfactory.

Even when they are combined, these two rates are, to some extent, inadequate or at least not an elegant combination, which is again due to the different denominators used in their calculations. Although they are sometimes presented in culinary terms as the doughnut (employment rate) and the hole (unemployment rate; Shiskin, 1976), they are not perfectly complementary. The fact that one measure is a percentage of the entire population (between certain age limits) and the other a percentage of the active population makes clear communication difficult. ${ }^{2}$

In this article, we use a different perspective to compare the labour market performances of the 20 largest OECD countries with each other and over time. More specifically, we follow a decomposition strategy in which the entire population (between age limits) is divided into three (or four) meaningful groups. The unemployment-to-population ratio and the inactivity-to-population ratio are put forward as a method for capturing the status of a labour market as adequately as possible within the limitations imposed by the use of not more than two indicators. Based on this decomposition and these indicators, we introduce the iceberg metaphor for the labour market. This image has been used in other contexts throughout the decades (e.g., in psychology for distinguishing between and examining the relationship of the unconscious and conscious mind, and in cultural studies for capturing the idea that for each distinct culture, there are visible and invisible aspects; Oberg, 1960; Petersen, 2007). However, as far as we know, the iceberg has not yet been applied in peer-reviewed labour market literature. Finally, based on this framework, we draw policy lessons for the 20 largest OECD countries.

With this study, we contribute to recent scientific literature in which so-called dashboard indicators for the labour market are presented (Brandolini and Viviano, 2016; Shorrocks, 2009). In other words, instead of looking for a single, superior measure with which to map the health of a labour market, we propose a (parsimonious) combination of two indicators. Our approach has two main advantages in addition to those mentioned above: (i) we only use statistical information that is already publicly available for most countries and (ii) the proposed measures are easy to understand. ${ }^{3}$

\footnotetext{
2 Moreover, while the employment rate is always calculated for a certain working-age population (see also the next section of this article), the unemployment rate is often measured for the whole active population (without any age limits).

3 The failure to meet these benefits is a criticism put forth by Brandolini and Viviano (2016) with regards to a contrasting approach in the literature, namely, that of the experience-weighted indices. In these indices, workers are weighted according to the number of hours worked, and non-working people are weighted according to their job opportunities (Hornstein et al., 2014a; Paul, 1992).
} 


\section{The iceberg decomposition}

According to the ILO definition, the (economically) active population comprises 'all persons of either sex who furnish the supply of labour for the production of economic goods and services, during a specified time-reference period' (ILO, 2016). This active population $(A)$ is also sometimes referred to as the labour force. The fraction $(a)$ of the total population $(P)$ in a country belonging to the labour force is referred to as the global activity rate or global participation rate:

$$
a=A / P \text {. }
$$

Because the youngest and oldest age groups are generally not active, in practice, the focus is more on the fraction ( $\left.a^{\prime}\right)$ of the working-age population that belongs to the active population:

$$
a^{\prime}=A / W \text {. }
$$

This fraction is called the activity rate or participation rate. The working-age population $(W)$ is the population within the age limits from which the working age population is recruited in principle. The age limits for the working-age population are, of course, arbitrary. The upper limit is usually 64 years-it is likely to be raised above this level in the near future though, as population is ageing and retirement age goes up (OECD, 2019b). ${ }^{4}$ The lower limit can be 15 years (i.e., the compulsory full-time educational upper age limit in many OECD countries), 20 years (i.e., the age at which compulsory full-time education is ended in all countries) or 25 years (i.e., the age at which most of the young people have completed their studies in all countries). In the present study, we will calculate statistics for the 25- to 64-year-old group. This choice is mainly prompted by the fact that we want to make country comparisons and do not want to introduce biases due to differences in the average graduation age across countries. It goes without saying that active individuals outside these limits are not included in the numerator in Eq. (2). Thus, the values for $A$ may differ in Eqs. (1) and (2).

The activity rate obviously hides the different participation modes of workers and jobseekers; hence, the performance of the labour market is not typically expressed in terms of the activity rate but rather in terms of the unemployment rate and/or the employment rate (see the introduction). The unemployment rate (ur) indicates, by definition, what fraction of the active population is seeking work $(U)$ :

$$
u r=U / A \text {. }
$$

Again, this is the unemployment rate among the working-age population, here defined as the 25- to 64-year-old group. As the active population breaks down into employed $(E)$ and unemployed, it can also be calculated as follows:

$$
u r=U /(E+U) \text {. }
$$

The employment rate $(e)$ or employment-to-population ratio is, by convention, expressed as the fraction of the workingage population that is employed:

$$
e=E / W \text {. }
$$

Comparing (the denominator) of Eqs. (3) and (5) underlines the limited complementarity of the unemployment rate and the employment rate mentioned in the introduction.

Those individuals who belong to the working-age population but not to the labour force are called inactive. They do not have a job but, unlike the unemployed, they are not looking for one either. Examples of inactive people are, as aforementioned, househusbands and housewives, the long-term sick and disabled (without an employment contract) and early retirees. Their numbers $(I)$ can be calculated as follows:

$$
I=W-A=W-E-U .
$$

Again, only the inactive, the employed and the unemployed within the working-age population are included in this calculation.

Based on the former definitions, the unemployment-to-population $(u)$ and inactivity-to-population $(i)$ ratios, which take a central position in the present study, can be introduced:

$$
\begin{gathered}
u=U / W \\
i=I / W .
\end{gathered}
$$

The elegance of these ratios lies in the fact that, together with the employment-to-population ratio, they sum to 1 for each country at any time:

$$
e+u+i=(E+U+I) / W=W / W=1=100 \% .
$$

Moreover, these ratios form an elegant ensemble with the activity rate:

$$
a^{\prime}=e+u=1-i \text {. }
$$

\footnotetext{
4 In contrast to our strategy, ILO (2013, p. 13) argues that 'no upper age limit should be set, so as to permit comprehensive coverage of work activities of the adult population and to examine transitions between employment and retirement.'
} 


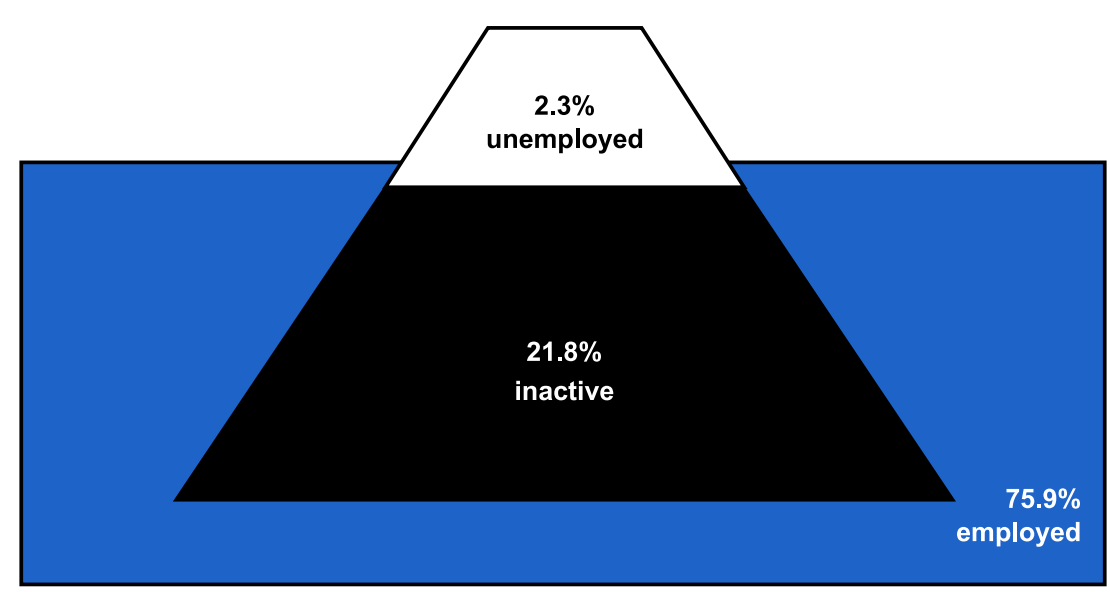

United States, 2019

Fig. 1. Iceberg representation of the 2019 labour market (25-64 years old) in the United States. Source: see Table A.1.

The unemployment-to-population and inactivity-to-population ratios can be easily calculated on the basis of the classical unemployment and employment rates among the working-age population, as follows: ${ }^{5}$

$$
\begin{aligned}
& u=u r \cdot e /(1-u r) \\
& i=1-(u r \cdot e) /(1-u r)-e .
\end{aligned}
$$

Although the complementarity and elegance of the unemployment-to-population and inactivity-to-population ratios make them extremely attractive, we are not aware of studies that consider them together in an in-depth manner. As far as we know, the inactivity-to-population ratio is only mentioned in three-particularly recent-articles (Artuc et al., 2019; Faggio, 2019; Vasić, 2019).

Taken together, the unemployment-to-population ratio and inactivity-to-population ratio represent the fraction of the working-age population that is not employed, sometimes referred to as the labour reserve. Because the unemploymentto-population ratio is much lower than the inactivity-to-population ratio in all OECD countries, we portray this labour reserve as like an iceberg, where the first percentage is the dot above the water, and the second ratio is the much larger reserve under the waterline. ${ }^{6}$ This metaphor captures the idea that most OECD countries, despite the substantial size of the pool of inactive people, have historically neglected to include this latent labour reserve in their labour market policies (see above).

\section{The iceberg in OECD labour markets}

\subsection{Unemployment-to-population and inactivity-to-population ratios in the OECD}

Fig. 1 shows the unemployment-to-population ratio and inactivity-to-population ratio for the United States in 2019, which is the largest OECD country by population (source: OECD, historical population, 2019). These ratios, together with the employment-to-population ratio and the classical unemployment rate, are listed in Table A.1 in Appendix for the 20 largest OECD countries by population. The calculations are based on publicly available OECD data for the employmentto-population ratio and the classical unemployment rate and therefore follow the definitions for these statistics given in the introduction.

The 25-64 age group in the United States in 2019 can be divided into 2.3\% unemployed, $21.8 \%$ inactive and $75.9 \%$ employed. While the search bar for the New York Times for November 2019 provides more than 110,000 hits for 'unemployment', of which more than 20,000 are for the 'unemployment rate', and fewer than 30,000 hits for 'inactivity'

\footnotetext{
5 Eq. (12) is trivial given Eqs. (9) and (11). The proof for Eq. (11) is based on Eqs. (7), (2), (3) and (9) $u=U / W=U \cdot a^{\prime} / A=u r \cdot(e+u)=u r \cdot e+u r \cdot u \Longleftrightarrow u-u r \cdot u=u r \cdot e \Longleftrightarrow u=u r \cdot e /(1-u r)$

6 It goes without saying that some subgroups of the inactive group, such as long-term sick and early retirees, cannot be activated anymore. We return to this point when discussing the limitations of our study in the Conclusion section.
} 


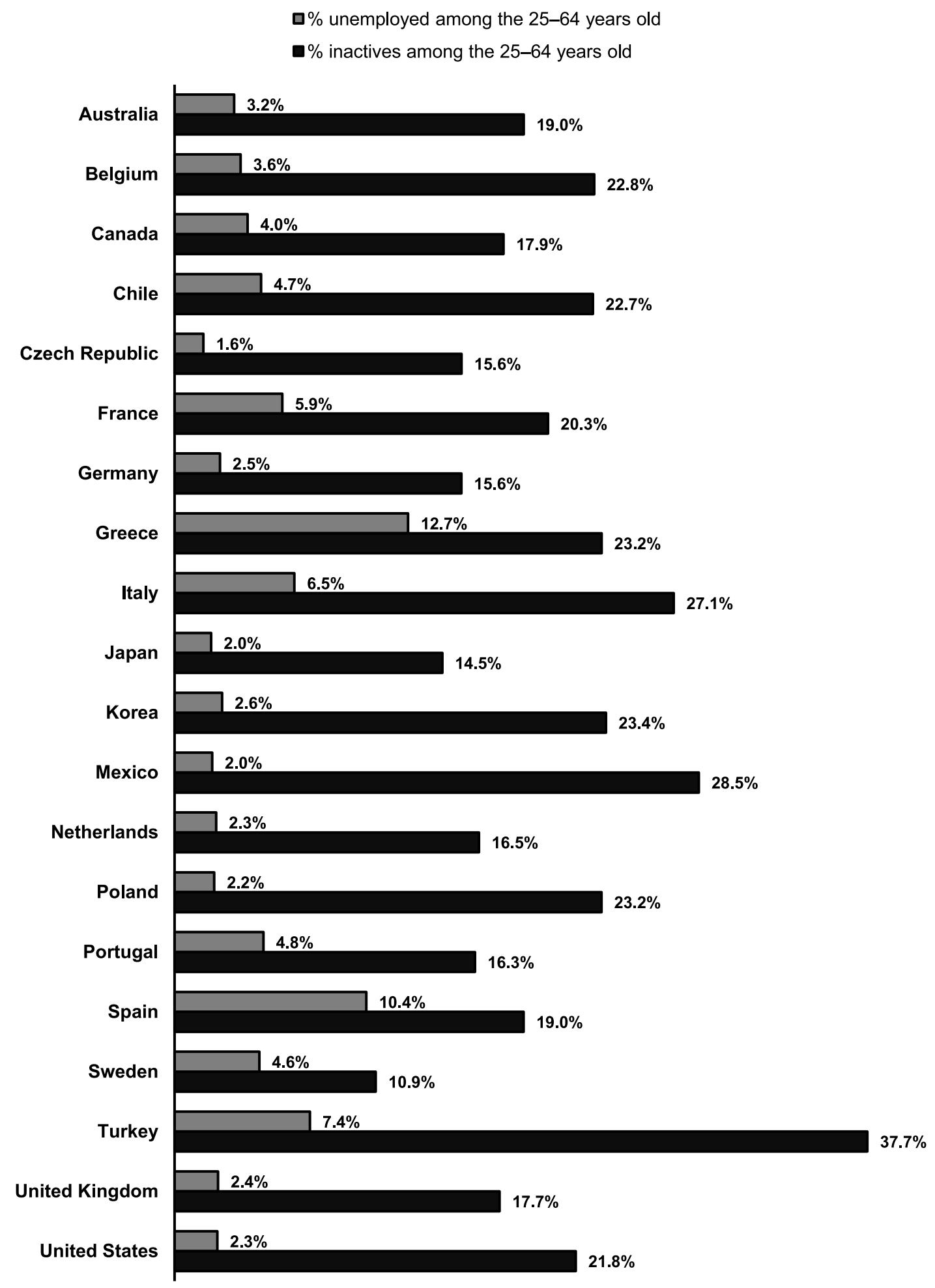

Fig. 2. Unemployment-to-population and inactivity-to-population ratios in the 20 largest OECD countries in 2019. Source: see Table A.1. 


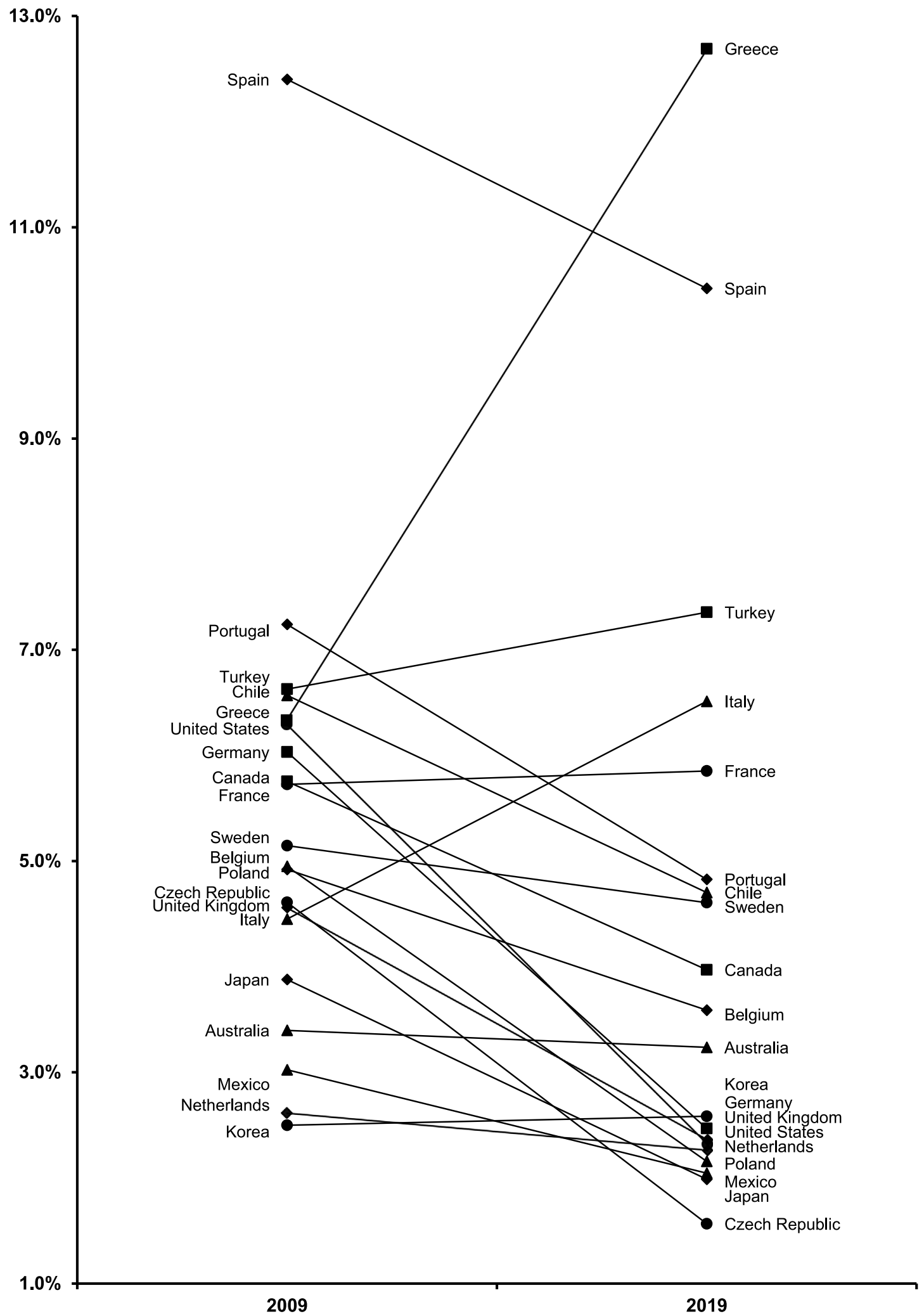

Fig. 3. Evolution in the unemployment-to-population ratios of the 20 largest OECD countries. Source: see Table A.1. 

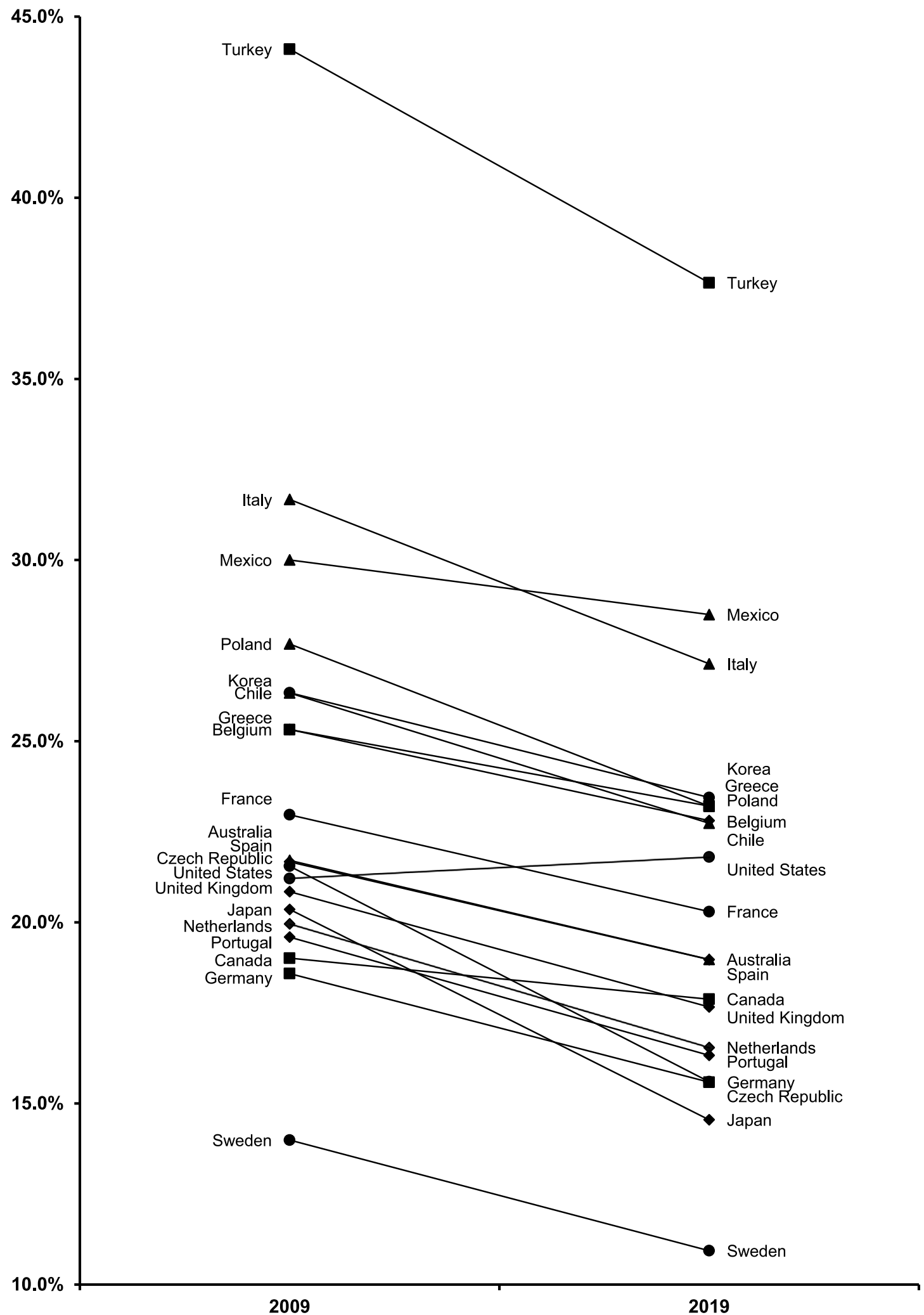

Fig. 4. Evolution in the inactivity-to-population ratios of the 20 largest OECD countries. Source: see Table A.1. 


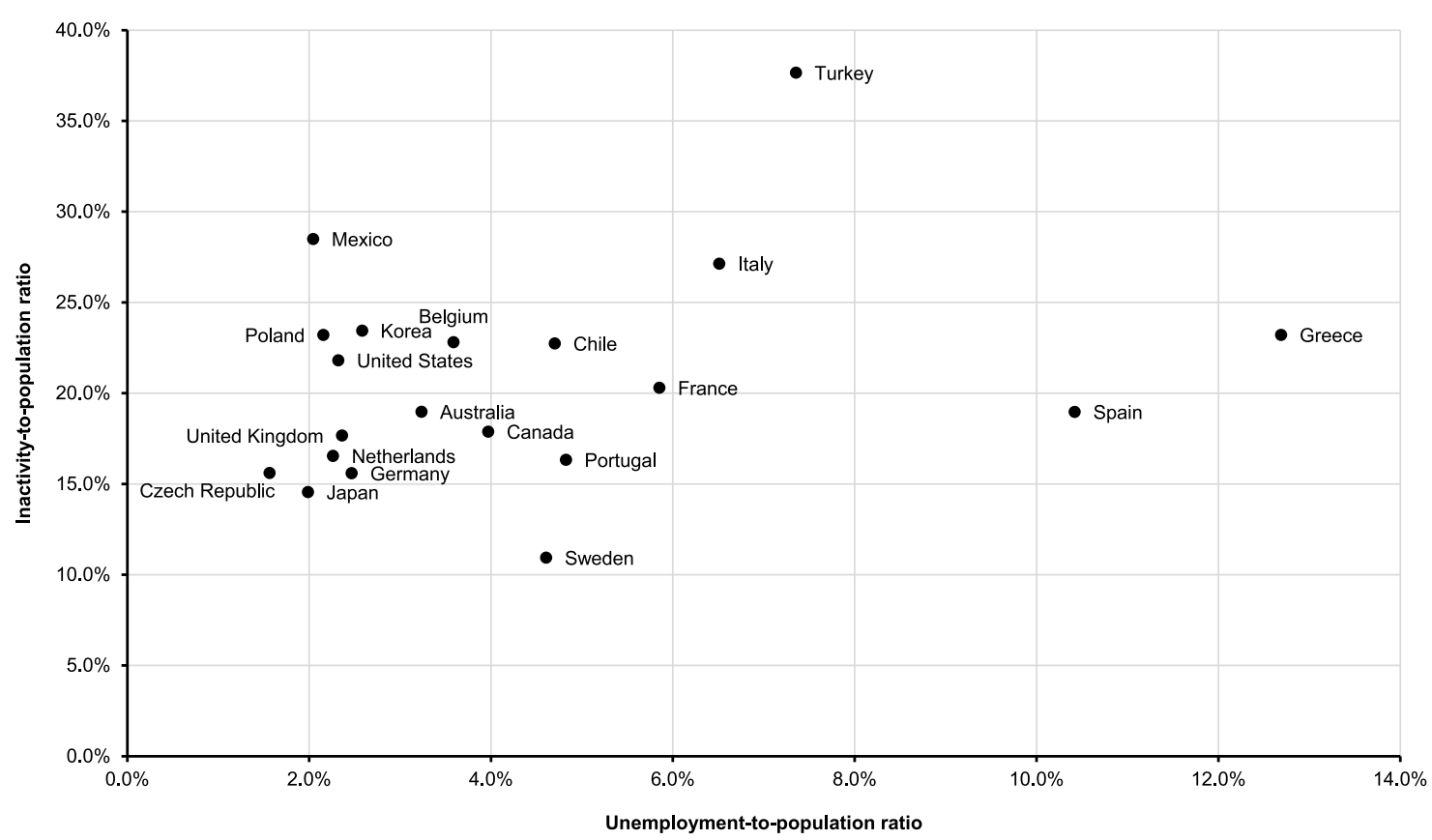

Fig. 5. Scatter plot of unemployment-to-population and inactivity-to-population ratios in the 20 largest OECD countries in 2019. Source: see Table A.1.

( 0 for the 'inactivity rate'), the proportion of inactive people in the United States turns out to be more than nine times higher than the proportion of unemployed individuals. Again, this supports the iceberg representation introduced above.

Fig. 2 presents the same data for the remaining 19 large OECD countries (Fig. A.1 is an alternative representation that also shows the proportion of working people). The right-hand side in Figs. 3 and 4 represents the countries' rankings in 2019 according to the unemployment-to-population and inactivity-to-population ratio, respectively. The average unemployment-to-population ratio is $4.6 \%$ (with a standard deviation of 2.9 percentage points), and its median is $3.4 \%$. The mean value of the inactivity-to-population ratio is $20.7 \%$ (with a standard deviation of 5.8 percentage points), and its median value is $19.6 \%$.

The highest proportions of unemployed individuals are found in Greece (12.7\%) and Spain (10.4\%), while the highest proportions of inactive individuals are found in Turkey (37.7\%) and Mexico (28.5\%). It is worth noting that Mexico's high inactivity is counterbalanced by a distinctively low unemployment-to-population ratio (2.0\%)-we return to this observation below. Low unemployment-to-population ratios are also observed in the Czech Republic (1.6\%), Japan (2.0\%), Poland (2.2\%), the Netherlands (2.3\%), United Kingdom (2.4\%), Germany (2.5\%) and Korea (2.6\%). As far as the inactivity-topopulation ratio is concerned, Sweden is the country with the lowest proportion of inactive individuals (10.9\%). Here too, Japan (14.5\%), the Czech Republic (15.6\%) and Germany (15.6\%) perform very well, with very low proportions of inactive people.

The Pearson correlation coefficient between the unemployment-to-population and inactivity-to-population ratios for the 20 largest OECD countries is 0.284 , indicating a medium correlation. Both ratios are logically related to each other but provide additional information separately, which again supports our dashboard approach of using both indicators.

Due to the different denominators used in the classical unemployment rate (active population as the denominator) and the unemployment-to-population ratio (working-age population as the denominator), the ratios lead to different rankings for the countries considered. These rankings are shown in Fig. A.2. Countries with a high proportion of inactive people do better (in terms of being relatively lower) with the unemployment-to-population ratio as opposed to the unemployment rate. For example, Mexico has the third lowest unemployment-to-population ratio but only the seventh lowest unemployment rate. Chile and the United States are also doing relatively better when examined using the unemployment-to-population ratio as opposed to the unemployment rate. Germany, with a very low proportion of inactive people, is doing better according to the unemployment rate (sixth least) than according to the unemploymentto-population ratio (eighth least). These results underline the discussion in the introduction: because the proportion of inactive people is completely excluded from the calculation of the traditional unemployment rate, it does not give a perfect picture of the percentage of unemployed individuals within the entire working-age population. 


\subsection{Time evolution}

Because they are calculated at any time against the entire working-age population, the time evolutions in the unemployment-to-population ratio and inactivity-to-population ratio always perfectly indicate increases and decreases in the proportions of unemployed and inactive individuals, respectively. In contrast, a lower unemployment rate over time can occur when the proportion of unemployed within the working-age population has not decreased, but some inactive individuals became employed. ${ }^{7}$

Fig. 3 presents a comparison of the unemployment-to-population ratios between 2009 (i.e., when the financial crisis of 2007-2008 started to substantially affect the labour market) and 2019 for the 20 largest OECD countries. Fig. 4 does the same for the inactivity-to-population ratio.

The evolution in the unemployment-to-population ratio is mixed: five countries recorded an increase (France, Greece, Italy, Korea and Turkey), while fifteen countries had a lower unemployment-to-population ratio in 2019 compared with 2009 (Australia, Belgium, Chile, Canada, the Czech Republic, Germany, Japan, Mexico, the Netherlands, Poland, Portugal, Spain, Sweden, the United Kingdom and the United States). The most pronounced trends towards a higher proportion of unemployed are for Greece (from $6.3 \%$ to $12.7 \%$ ) and Italy (from $4.5 \%$ to $6.5 \%$ )-we return to these worrying indicators below. A notable decrease occurred in the United States (from 6.3\% to 2.3\%), Germany (from 6.0\% to 2.5\%) and the Czech Republic (from $4.6 \%$ to $1.6 \%$ ).

The mixed evolution of the unemployment-to-population is offset by a decrease in the inactivity-to-population ratio between 2009 and 2019 in all countries except the United States (from 21.2\% to 21.8\%). The strongest decreases were in Turkey (from 44.1\% to 37.7\%), the Czech Republic (from 21.6\% to 15.6\%) and Japan (from 20.4\% to 14.5\%). Here, too, Germany shows a remarkably favourable evolution, with its inactivity-to-population ratio declining from $18.6 \%$ to $15.6 \%$.

\subsection{Policy perspective}

As mentioned previously, increasing the employment rate, as aimed for by many countries, may require different policies, depending on the relative size of the unemployment-to-population and inactivity-to-population ratios. A relatively high level of inactivity requires a focus on supply-oriented measures, while a high level of unemployment requires (in addition) a focus on stimulating the demand for labour (e.g., via government investments) and the matching of supply and demand (e.g., via additional sources for, and reforms in, the country's public employment agencies and its active labour market policies). The scatter plot in Fig. 5 compares the two measures for the 20 largest OECD countries in 2019. On the basis of this scatter plot and the aforementioned average and median values of the unemployment-to-population and inactivity-to-population ratios, seven groups of countries stand out in terms of desired policy focus.

First, there is a group of exemplary countries-in terms of the macro-economic health of their labour markets (we will refer to other facets below)-with a low to medium unemployment-to-population ratio combined with a low to medium inactivity-to-population ratio. These are the Czech Republic, Germany, Japan, the Netherlands, Sweden and the United Kingdom. Sweden, with its very low inactivity-to-population ratio (see above), seems to be particularly inspiring with regards to its supply-related choices (such as support for employees through childcare and mobility and the pension system). The Czech Republic, Germany, Japan, the Netherlands and the United Kingdom score remarkably well with respect to their lower unemployment-to-population ratios, so, in particular, other countries need to examine the active labour market policies (activation of the unemployed and matching vacancies) and job creation strategies of these exemplary countries. $^{8}$

The second group of countries, i.e., Poland, Korea and the United States, is very similar to the latter group in terms of the low unemployment-to-population ratio (around 2.5\%) but show a medium-high inactivity-to-population ratio $(21.8 \%$ to $23.4 \%$ ). If these countries want to increase their employment rate, they will have to look first and foremost at the activation of inactive people (and thus a supply-oriented policy).

A third group, consisting of Australia, Belgium, Canada, Chile and Portugal, is characterised by both an average unemployment-to-population ratio (between $3.2 \%$ and $4.8 \%$ ) and a medium-to-low, medium or medium-to-high inactivity-to-population ratio (between $16.3 \%$ and $22.8 \%$ ). These countries need to focus on multiple facets of their labour market policies in order to match the exemplary countries. Within this group, the challenge lies more in the activation of the unemployed in the case of Portugal, while, in Belgium, the labour reserve in terms of the inactive population requires particular attention. ${ }^{9}$

A fourth group containing France-this country sits on the edge of the previous group-and Spain is characterised by an average inactivity-to-population ratio and a high unemployment-to-population ratio. Although France and Spain both

\footnotetext{
7 Let the unemployment-to-population ratio be $2.0 \%$ in year $y$ and $2.1 \%$ in year $y+10$, while the employment-to-population ratio rises from $75.0 \%$ to $85.0 \%$, respectively. Then the unemployment rate will be higher in year $y(2.6 \%)$ than in year $y+10(2.4 \%)$.

8 These countries' position as exemplary countries is also stressed, based on related measures, in ILO (2016), OECD (2017b) and OECD (2019a).

9 This is in line with extensive policy reports focussing relatively more on high unemployment for Portugal while stressing general non-employment for Belgium (ILO, 2017; OECD, 2015b, 2017a).
} 
have a labour reserve of inactive and unemployed persons and can rely on both groups to increase their employment rates, policies aimed at helping the unemployed find work are required in these countries. ${ }^{10}$

Greece is characterised by the same problem (i.e., a high unemployment-to-population ratio) but also has a mediumhigh inactivity-to-population ratio, thus meriting its own, fifth group. A sixth group consists of Italy and Turkey, with high unemployment-to-population ratios and high inactivity-to-population ratios. In these fifth and sixth groups of countries, bold reforms mirroring those of the exemplary countries, on both the supply and demand sides, are emerging.

Finally, Mexico (seventh group) is an outlier, as it combines a high inactivity-to-population ratio with a low unemployment-to-population ratio, as indicated above. If this country wants to achieve a higher employment rate (e.g., to build a stronger welfare state), it should focus on the latent labour reserve of inactive people and a supply-oriented reform agenda. $^{11}$

\subsection{Extended decomposition}

The division of the working-age population into the fractions employed, unemployed and inactive gives equal weight to every unemployed person, regardless of their length of unemployment. Recent literature criticises the classical unemployment rate on this basis (Bazen et al., 2014; Brandolini and Viviano, 2016). Indeed, two countries can record the same unemployment rate, while the average distance from the labour market for the group of unemployed people in one country can differ fundamentally from that in the other, so that the overall unemployment-to-population ratio in the latter country is more worrying (Hornstein et al., 2014a,b; Krueger et al., 2014). In particular, the average unemployment duration of the unemployed in these countries may differ. A longer period of unemployment is seen in welfare economics as an aggravated form of unemployment. Research shows that unemployment has a self-reinforcing effect due to the psychosocial problems it causes (Bazen et al., 2014) and the unfavourable gap it leaves on a CV when applying for a job (Baert and Verhaest, 2019; Eriksson and Rooth, 2014; Kroft et al., 2013; Van Belle et al., 2018). Short-term unemployment, on the other hand, may simply be an indication of a more flexible labour market on its way to a better allocation of labour (Borjas, 2015; Cahuc and Zylberberg, 2006).

These arguments also apply to the unemployment-to-population ratio that is central to this study. Therefore, as an extended decomposition in Fig. A.3 and an extended iceberg representation in Fig. A.4, we divide this fraction of unemployed within the working-age population into a fraction of unemployed with an unemployment duration of less than one year and a fraction of unemployed with an unemployment duration of one year or more. The first category is seen by the ILO as short-term unemployed, the second as long-term unemployed (ILO, 2016).

Fig. A.4 shows that in the United States, only a very small fraction of the unemployed are long-term unemployed $(0.3 \%$ of the working-age population). In addition, in Korea and Mexico, there are hardly any or no long-term unemployed. In other countries, this fraction is much higher. Greece, Spain and Italy are the leaders with $9.1 \%, 4.3 \%$ and 3.8\% long-term unemployed, respectively, among their working-age populations. Thereby, in Greece and Italy, the proportion long-term unemployed is even higher than the proportion of short-term unemployed. Therefore, a strengthened active labour market policy in combination with a general stimulation of the economy (see above), possibly in combination with a reform in unemployment benefits, appears to be needed across Southern Europe. Remarkably, also in Belgium, the proportions of short-term and long-term unemployed are equal (i.e. 1.8\%).

\section{Conclusion}

In this article, we defended the unemployment-to-population ratio and the inactivity-to-population ratio as two crucial indicators capturing the macro-economic health of a labour market by means of a parsimonious dashboard approach. We argued that these measures are much more complementary than the traditional unemployment and employment rates, which are not calculated using the same population and are therefore, to some extent, incorrectly presented as the doughnut and the hole of the labour market. We replaced this metaphor with a new one, namely that of the iceberg. While countries have historically focused on the activation of unemployment (and thus on reducing the unemploymentto-population ratio), a much larger labour reserve of inactive individuals remained below the waterline. The additional advantages of the unemployment-to-population and inactivity-to-population ratios are that they are easy to understand and can be calculated based on the widespread unemployment and employment rates, in contrast to the more complex dashboard approaches proposed in the literature.

Based on their relative unemployment-to-population and inactivity-to-population ratios, we assigned the 20 largest OECD countries to what appears to be their desired primary labour market focus. For example, countries such as Poland,

\footnotetext{
10 In this respect, OECD (2015a, p. 19) mentions that 'expenditures on active labour market programmes are not high compared to other OECD countries, particularly when considering the numbers of unemployed people in Spain' and proposes targeted activation strategies.

11 OECD (2017c, p. 2), advocates in this respect in particular '[making] paid employment more attractive to women by improving the compatibility of employment and family life through efforts to reduce long working hours' and '[improving] the quality of teaching and promoting better school-to-work transition to help reduce early school leaving.'
} 
Korea and the United States had in 2019 a limited proportion of unemployed but a high proportion of inactive persons among their working-age population, while in countries such as France and Spain, the opposite was true. For the first group of countries, therefore, the focus should be relatively more on supply-oriented policies, while for the second group, stimulating the demand for labour and matching of supply and demand seem to be relatively more important.

We end this article by acknowledging the limitations of our approach. First, although the defended indicators can be applied to any definition of employment, unemployment and inactivity, we have followed the ILO definitions fully. Mindful of Sen (1976), we focused on the 'aggregation problem' at the expense of not focusing on the 'identification problem'. This is a conscious focus, which however does not imply that we would consider the identification problem unimportant. On the contrary, as also argued by an anonymous reviewer of a former version of this article, the boundaries between the labour market states 'employed', 'unemployed' and 'inactive' have been blurred, e.g., due to the spreading of gig jobs and non-market voluntary activities. Therefore, recent research related to this identification problem focusses on the crucial distinction between workers by attachment to the labour market (Jones and Riddell, 2019). As the proportion of marginally attached and unattached among the inactive may differ between countries, this limits our cross-country comparisons of inactivity-to-population ratios. We return to this issue below.

Second, but related to the first limitation, we must acknowledge that limited differences exist in the way countries collect the employment and unemployment data made available by the ILO (Filipi, 2016; ILO, 2018), due to ambiguities in the genesis and interpretation of the labour force questionnaires following the ILO standard (Sengenberger, 2011), which implies that the country comparisons in this study cannot be interpreted absolutely.

Third, we took a monolithic view of the group of employed. However, workers are also heterogeneous, for example because some work full-time and some part-time (Brandolini and Viviano, 2018; ECB, 2017; OECD, 2019a; Sengenberger, 2011; Taylor et al., 2017). The Netherlands, for example, has one of the highest levels of employment-we labelled it as an exemplary country given its low unemployment-to-population and inactivity-to-population ratios-but when the employment rate is expressed in full-time equivalents (FTE), the Netherlands is one of the less-well-performing countries (Brandolini and Viviano, 2018). The overall quality of work and inequality in the division of its product among workers was also left out of consideration, while recent scientific research indicates that major problems arise in this area across the OECD countries (Baert, 2018; Green and Mostafa, 2012). Follow-up research could propose an extended decomposition strategy that better captures the heterogeneity among the employed group. At the same time, we believe that our headcount approach remains relevant anyway because it gives a clear indication of the number of workers sustaining social security systems (and thereby counteracting the consequences of an ageing population in many OECD countries). Moreover, research has shown beyond a doubt that a job, whether temporary or permanent, part-time or full-time, is important for the self-confidence and social integration of individuals (Brandolini and Viviano, 2016, 2018).

Fourth, we also considered the group of inactive people as a homogeneous group in our decomposition. However, the further subdivision of the inactive group into underlying groups such as the discouraged unemployed, the long-term sick, pensioners who have retired early and househusbands and housewives, can provide an even better indication of what areas labour market-related reforms in the various OECD countries should target (Eurostat, 2018). Also a broader division of the inactive group into those who could in principle be activated and those for whom this is impossible would be useful.

Fifth, but related to the first and fourth limitation, the composition of the inactive group may differ between countries. In particular, as argued by an anonymous reviewer of a former version of this article, the proportion of the working-age population that is never employable varies across countries for a number of reasons, among which the diverse generosity of pensions systems. This observation places certain limits on the cross-country comparison of inactivity-to-population ratios, although many reasons for diverging inactivity can in principle be influenced by policy.

Last, in the present study we applied our iceberg decomposition to data for 2019, i.e. data from before the COVID-19 crisis. Whereas figures on employment, unemployment and inactivity varied only moderately from year to year in recent years, data for 2020 are likely to differ substantially from those for 2019 for many countries. However, we are convinced that our parsimonious dashboard approach will be all the more useful to monitor the potential damage of the COVID-19 crisis in the various OECD countries in the coming years. Which countries have succeeded better than others in limiting this damage on the labour market? In which countries has this crisis pushed employees out of the labour market or created mass unemployment? The evolution of unemployment-to-population and inactivity-to-population ratios, as mapped in Figs. 3 and 4, or as captured by a version of Fig. 5 in which the axes represent time evolutions, shows it at a glance. This contrasts sharply with a classical comparison based on unemployment rates, which may mask potentially different inflow into inactivity dynamics between countries.

\section{Declaration of competing interest}

The authors declare that they have no known competing financial interests or personal relationships that could have appeared to influence the work reported in this paper. 


\section{Appendix}

See Figs. A.1-A.2 and Table A.1.

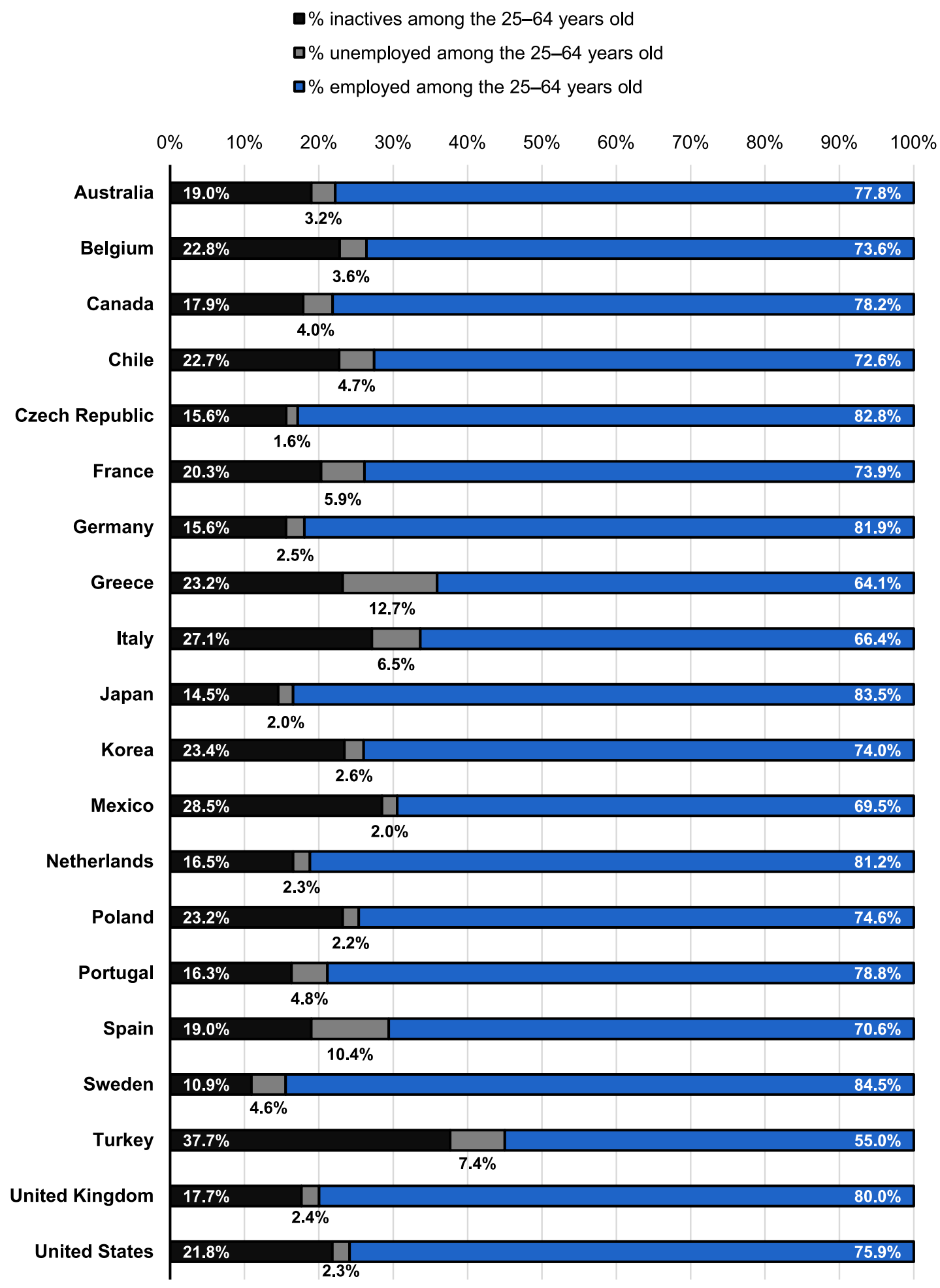

Fig. A.1. Decomposition of 25- to 64-year-olds by employment status in the 20 largest OECD countries in 2019. Source: see Table A.1. 


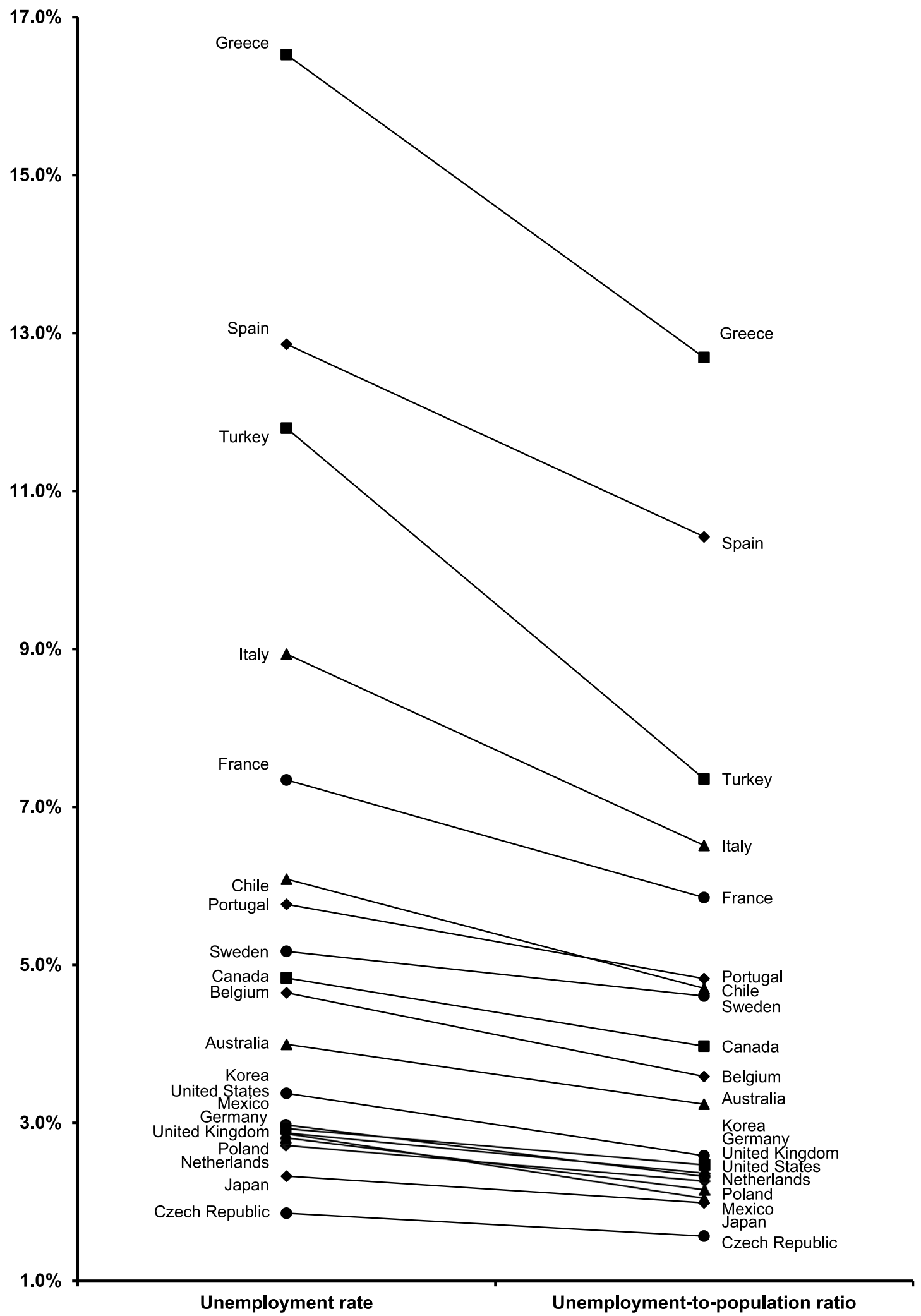

Fig. A.2. Unemployment rate versus unemployment-to-population ratio for the 20 largest OECD countries in 2019. Source: see Table A.1. 


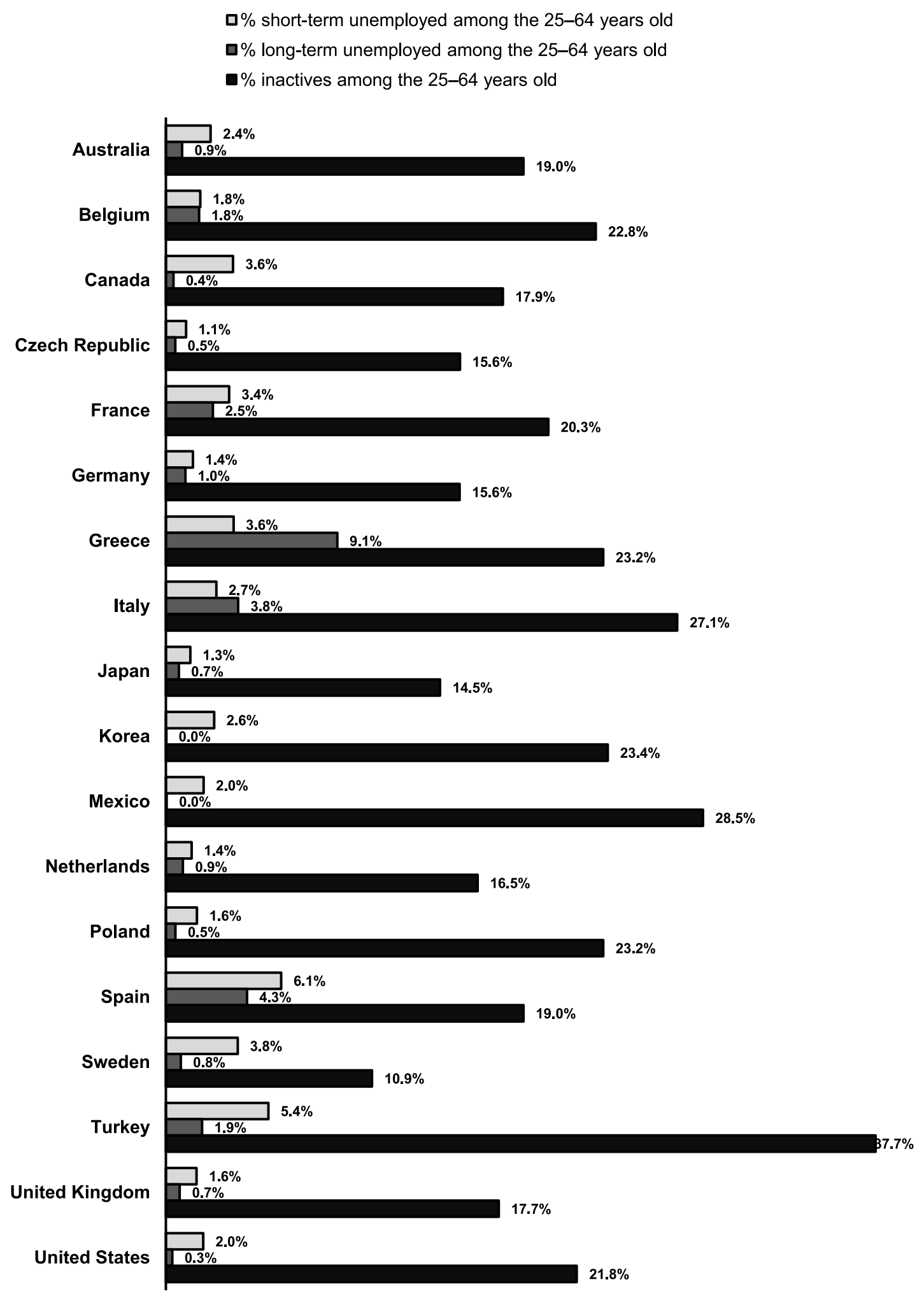

Fig. A.3. Short-term-unemployment-to-population, long-term-unemployment-to-population and inactivity-to-population ratios for the 20 largest OECD countries in 2019.

Source: Author's calculations based on Table A.1 and OECD's Dataset 'Unemployment by duration'. In the latter dataset, information on Chile and Portugal was lacking. 


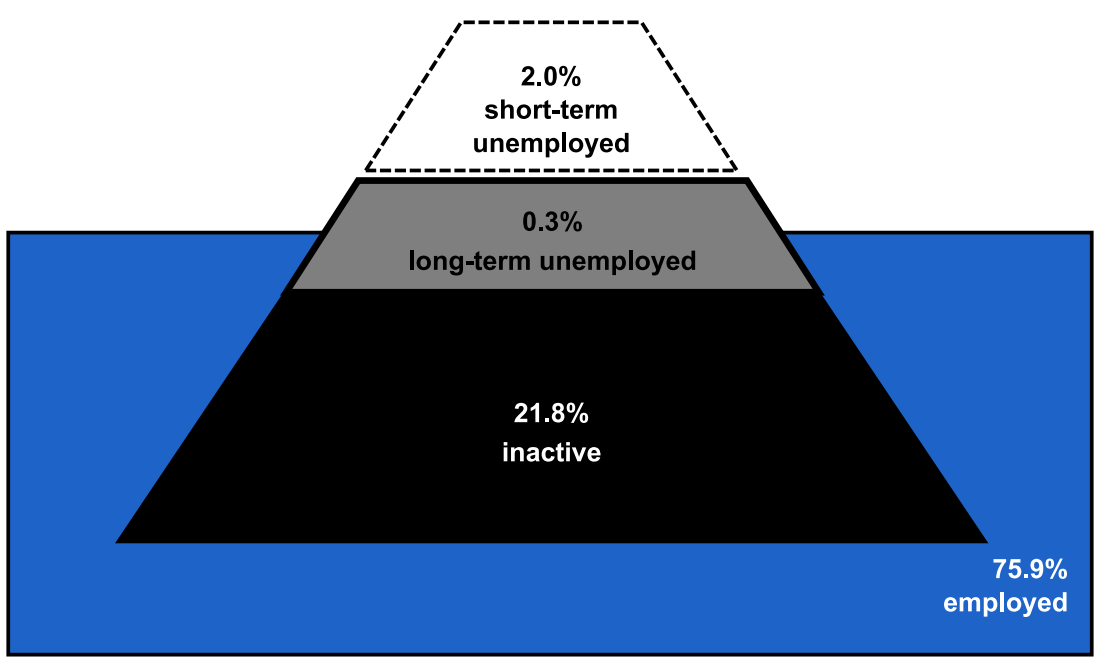

United States, 2019

Fig. A.4. Extended iceberg representation of the 2019 labour market in the United States. Source: Author's calculations based on Table A.1 and OECD's Dataset 'Unemployment by duration'.

Table A.1

Data description.

\begin{tabular}{|c|c|c|c|c|c|c|c|c|}
\hline & \multicolumn{2}{|c|}{$\begin{array}{l}\text { Employment-to-population } \\
\text { ratio }\end{array}$} & \multicolumn{2}{|c|}{ Unemployment rate } & \multicolumn{2}{|c|}{$\begin{array}{l}\text { Unemployment-to-population } \\
\text { ratio }\end{array}$} & \multicolumn{2}{|c|}{ Inactivity-to-population ratio } \\
\hline Description & \multicolumn{2}{|c|}{$\begin{array}{l}\text { Percentage employed among } \\
\text { all 25- to 64-year-olds } \\
\text { (according to the ILO } \\
\text { definition; see the } \\
\text { introduction of the present } \\
\text { article). This ratio is also } \\
\text { known as the employment } \\
\text { rate. }\end{array}$} & \multicolumn{2}{|c|}{$\begin{array}{l}\text { Percentage unemployed } \\
\text { among the 25- to } \\
64 \text {-year-olds who are } \\
\text { unemployed or employed } \\
\text { (according to the ILO } \\
\text { definition; see the } \\
\text { introduction of the present } \\
\text { article). }\end{array}$} & \multicolumn{2}{|c|}{$\begin{array}{l}\text { Percentage unemployed } \\
\text { among all 25- to 64-year-olds } \\
\text { (according to the ILO } \\
\text { definition; see the } \\
\text { introduction of the present } \\
\text { article). }\end{array}$} & \multicolumn{2}{|c|}{$\begin{array}{l}\text { Percentage inactive persons } \\
\text { (i.e., not in employment or } \\
\text { unemployment) among all } \\
25 \text { - to } 64 \text {-year-olds. This } \\
\text { ratio is also known as the } \\
\text { inactivity rate. }\end{array}$} \\
\hline \multirow[t]{2}{*}{ Source } & \multicolumn{2}{|c|}{$\begin{array}{l}\text { OECD (LFS by sex and age, } \\
\text { Employment / population } \\
\text { ratio) }\end{array}$} & \multicolumn{2}{|c|}{$\begin{array}{l}\text { OECD (LFS by sex and age, } \\
\text { Unemployment rate) }\end{array}$} & \multicolumn{2}{|c|}{$\begin{array}{l}\text { Author's calculations (see } \\
\text { Eq. (11)). }\end{array}$} & \multicolumn{2}{|c|}{$\begin{array}{l}\text { Author's calculations (see } \\
\text { Eq. (12)). }\end{array}$} \\
\hline & 2009 & 2019 & 2009 & 2019 & 2009 & 2019 & 2009 & 2019 \\
\hline Australia & $74.9 \%$ & $77.8 \%$ & $4.3 \%$ & $4.0 \%$ & $3.4 \%$ & $3.2 \%$ & $21.7 \%$ & $19.0 \%$ \\
\hline Belgium & $69.8 \%$ & $73.6 \%$ & $6.6 \%$ & $4.6 \%$ & $4.9 \%$ & $3.6 \%$ & $25.3 \%$ & $22.8 \%$ \\
\hline Canada & $75.2 \%$ & $78.2 \%$ & $7.1 \%$ & $4.8 \%$ & $5.8 \%$ & $4.0 \%$ & $19.0 \%$ & $17.9 \%$ \\
\hline Chile & $67.1 \%$ & $72.6 \%$ & $8.9 \%$ & $6.1 \%$ & $6.6 \%$ & $4.7 \%$ & $26.3 \%$ & $22.7 \%$ \\
\hline Czech Republic & $73.8 \%$ & $82.8 \%$ & $5.9 \%$ & $1.9 \%$ & $4.6 \%$ & $1.6 \%$ & $21.6 \%$ & $15.6 \%$ \\
\hline France & $71.3 \%$ & $73.9 \%$ & $7.4 \%$ & $7.3 \%$ & $5.7 \%$ & $5.9 \%$ & $23.0 \%$ & $20.3 \%$ \\
\hline Germany & $75.4 \%$ & $81.9 \%$ & $7.4 \%$ & $2.9 \%$ & $6.0 \%$ & $2.5 \%$ & $18.6 \%$ & $15.6 \%$ \\
\hline Greece & $68.3 \%$ & $64.1 \%$ & $8.5 \%$ & $16.5 \%$ & $6.3 \%$ & $12.7 \%$ & $25.3 \%$ & $23.2 \%$ \\
\hline Italy & $63.9 \%$ & $66.4 \%$ & $6.5 \%$ & $8.9 \%$ & $4.5 \%$ & $6.5 \%$ & $31.7 \%$ & $27.1 \%$ \\
\hline Japan & $75.8 \%$ & $83.5 \%$ & $4.9 \%$ & $2.3 \%$ & $3.9 \%$ & $2.0 \%$ & $20.4 \%$ & $14.5 \%$ \\
\hline Korea & $71.2 \%$ & $74.0 \%$ & $3.4 \%$ & $3.4 \%$ & $2.5 \%$ & $2.6 \%$ & $26.3 \%$ & $23.4 \%$ \\
\hline Mexico & $67.0 \%$ & $69.5 \%$ & $4.3 \%$ & $2.9 \%$ & $3.0 \%$ & $2.0 \%$ & $30.0 \%$ & $28.5 \%$ \\
\hline Netherlands & $77.4 \%$ & $81.2 \%$ & $3.3 \%$ & $2.7 \%$ & $2.6 \%$ & $2.3 \%$ & $20.0 \%$ & $16.5 \%$ \\
\hline Poland & $67.4 \%$ & $74.6 \%$ & $6.8 \%$ & $2.8 \%$ & $4.9 \%$ & $2.2 \%$ & $27.7 \%$ & $23.2 \%$ \\
\hline Portugal & $73.2 \%$ & $78.8 \%$ & $9.0 \%$ & $5.8 \%$ & $7.2 \%$ & $4.8 \%$ & $19.6 \%$ & $16.3 \%$ \\
\hline Spain & $65.9 \%$ & $70.6 \%$ & $15.8 \%$ & $12.9 \%$ & $12.4 \%$ & $10.4 \%$ & $21.7 \%$ & $19.0 \%$ \\
\hline Sweden & $80.9 \%$ & $84.5 \%$ & $6.0 \%$ & $5.2 \%$ & $5.1 \%$ & $4.6 \%$ & $14.0 \%$ & $10.9 \%$ \\
\hline Turkey & $49.3 \%$ & $55.0 \%$ & $11.9 \%$ & $11.8 \%$ & $6.6 \%$ & $7.4 \%$ & $44.1 \%$ & $37.7 \%$ \\
\hline United Kingdom & $74.6 \%$ & $80.0 \%$ & $5.8 \%$ & $2.9 \%$ & $4.6 \%$ & $2.4 \%$ & $20.8 \%$ & $17.7 \%$ \\
\hline United States & $72.5 \%$ & $75.9 \%$ & $8.0 \%$ & $3.0 \%$ & $6.3 \%$ & $2.3 \%$ & $21.2 \%$ & $21.8 \%$ \\
\hline
\end{tabular}




\section{References}

Artuc, E., Christiaensen, L., Winker, H., 2019. Does automation in rich countries hurt developing ones? Evidence from the U.S. and Mexico. Available at: http://conference.iza.org/conference_files/worldbank_2019/winkler_h23742.pdf. (Accessed 18 July 2020).

Baert, S., 2018. Hiring discrimination: An overview of (almost) all correspondence experiments since 2005. In: Gaddis, Michael (Ed.), Audit Studies: Behind the Scenes with Theory, Method, and Nuance. Springer, New York.

Baert, S., Verhaest, D., 2019. Unemployment or overeducation: Which is a worse signal to employers? Economist 167 (1), 1-21.

Bazen, S., Joutard, X., Niang, M.M., 2014. The measurement of unemployment using completed durations: Evidence on the gender gap in unemployment in France. J. Econ. Inequal. 12 (4), 517-534.

Borjas, G.J., 2015. Labor Economics. McGraw-Hill, New York.

Brandolini, A., Viviano, E., 2016. Behind and beyond the (head count) employment rate. J. R. Stat. Soc.: Ser. A (Stat. Soc.) 179 (3), 657-681.

Brandolini, A., Viviano, E., 2018. Measuring employment and unemployment. IZA World Labor (445), http://dx.doi.org/10.15185/izawol.445.

Cahuc, P., Zylberberg, A., 2006. The Natural Survival of Work: Job Creation and Job Destruction in a Growing Economy. MIT Press, Cambridge.

Diamond, P., 2013. Cyclical unemployment, structural unemployment. National Bureau of Economic Research Working Paper Series, No. 18761.

ECB, 2017. Assessing labour market slack. ECB Econ. Bull. 2017 (3), 31-35.

Elsby, M.W.L., Hobijn, B., Şahin, A., 2015. On the importance of the participation margin for labor market fluctuations. J. Monetary Econ. 72, 64-82.

Eriksson, S., Rooth, D.-O., 2014. Do employers use unemployment as a sorting criterion when hiring? Evidence from a field experiment. Amer. Econ. Rev. 104 (3), 1014-1039.

European Commission, 2018. Employment and Social Developments in Europe. European Commission, Brussels.

Eurostat, 2018. Underemployment and potential additional labour force statistics. Available at: https://ec.europa.eu/eurostat/statistics-explained/index. php/Underemployment_and_potential_additional_labour_force_statistics. (Accessed 18 July 2020).

Faggio, G., 2019. Relocation of public sector workers: Evaluating a place-based policy. J. Urban Econ. 111, 53-75.

Filipi, G., 2016. Labour statistics in south-eastern Europe: Similarities and differences across national definitions. Int. Labour Rev. 155 (3), 461-470.

Green, F., Mostafa, T., 2012. Trends in Job Quality in Europe. Eurofound, Dublin.

Hornstein, A., Kudlyak, M., Lange, F., 2014a. Measuring resource utilization in the labor market. Fed. Reserve Bank Richmond Econ. Q. 100 (1), 1-21.

Hornstein, A., Kudlyak, M., Lange, F., Sablik, T., 2014b. Does the unemployment rate really overstate labor market recovery? Fed. Reserve Bank Richmond Econ. Brief (14-06).

ILO, 2008. Beyond unemployment: Measurement of other forms of labour underutilization. Room Document No. 13 Working Group on Labour Underutilization. In: 18th International Conference of Labour Statisticians. Geneva.

ILO, 2013. Resolution Concerning Statistics of Work, Employment and Labour Underutilization. International Labour Office, Geneva.

ILO, 2016. Key Indicators of the Labour Market, ninth ed. International Labour Office, Geneva.

ILO, 2017. Policy Brief on Labour Market Integration Measures for Young People. International Labour Office, Geneva.

ILO, 2018. Measuring Unemployment and the Potential Labour Force in Labour Force Surveys: Main Findings from the ILO LFS Pilot Studies. International Labour Office, Geneva.

Jones, S.R.G., Riddell, W.C., 2019. Unemployment, marginal attachment, and labor force participation in Canada and the United States. J. Labor Econ. 37 (S2), 399-441.

Kroft, K., Lange, F., Notowidigdo, M.J., 2013. Duration dependence and labor market conditions: Evidence from a field experiment. Q. J. Econ. 128 (3), 1123-1167.

Krueger, A.B., Cramer, J., Cho, D., 2014. Are the long-term unemployed on the margins of the labor market? Brook. Pap. Econ. Act. 2014, 229-299.

Oberg, K., 1960. Culture shock: Adjustment to new cultural environments. Pract. Anthropol. 7 (4), $177-182$.

OECD, 2015a. OECD Skills Strategy Diagnostic Report: Spain. OECD, Paris.

OECD, 2015b. OECD Skills Strategy Diagnostic Report: Portugal. OECD, Paris.

OECD, 2017a. Belgium Policy Brief-Helping Low-Educated Young People Who are at Risk of Being Left behind. OECD, Paris.

OECD, 2017b. OECD Employment Outlook 2017. OECD, Paris.

OECD, 2017c. Mexico Policy Brief-The NEET Challenge: Helping Jobless and Disengaged Youth. OECD, Paris.

OECD, 2019a. OECD Employment Outlook 2019. OECD, Paris.

OECD, 2019b. Pensions at a Glance 2019: OECD and G20 Indicators. OECD, Paris.

Paul, S., 1992. An illfare approach to the measurement of unemployment. Appl. Econ. 24 (7), $739-743$.

Petersen, C.A., 2007. A historical look at psychology and the scientist-practitioner model. Am. Behav. Sci. 50 (6), $758-765$.

Sen, A.K., 1976. Poverty: An ordinal approach to measurement. Econometrica 44 (2), 219-231.

Sengenberger, W., 2011. Beyond the Measurement of Unemployment and Underemployment: The Case for Extending and Amending Labour Market Statistics. ILO, Geneva.

Shiskin, J., 1976. Employment and unemployment: The doughnut or the hole? Monthly Labor Rev. 99 (2), 3-10.

Shorrocks, A., 2009. On the measurement of unemployment. J. Econ. Inequal. 7 (3), 311-327.

Sylla, N.S., 2013. Measuring labour absorption problems in developing countries: Limitations of the concept of unemployment. Int. Labour Rev. 152 (1), 27-41.

Taylor, M., Marsh, G., Nicol, D., Broadbent, P., 2017. The Taylor review of modern working practices. Available at: https://www.gov.uk/government/ publications/good-work-the-taylor-review-of-modern-working-practices. (Accessed 18 July 2020).

Van Belle, E., Di Stasio, V., Caers, R., De Couck, M., 2018. Why are employers put off by long spells of unemployment? Eur. Sociol. Rev. 34 (6), 694-710.

Vasić, V., 2019. Skills Mismatch Measurement in Serbia. European Training Foundation, Turin. 